\title{
Correlation Between Quality of Life and Severity of Valve Abnormalities in Children with Rheumatic Heart Disease
}

\author{
I Gusti Ayu Trisna Windiani*, Putu Diah Vedaswari, Eka Gunawijaya, \\ Ni Putu Veny Kartika Yantie, I Gusti Agung Ngurah Sugitha Adnyana, Soetjiningsih
}

Department of Child Health, Udayana University Medical School, Sanglah Hospital, Denpasar, Indonesia

\author{
Email address: \\ trisnawindianidr@yahoo.co.id (I G. A. T. Windiani),diah.vedaswari@gmail.com (P. D. Vedaswari), \\ ekagunawijaya@yahoo.com (E. Gunawijaya),kartika.veny@gmail.com (Ni P. V. K. Yantie), \\ sugad168@yahoo.com (I G. A. N. S. Adnyana),prof_soetji@yahoo.com (Soetjiningsih) \\ ${ }^{*}$ Corresponding author
}

\section{To cite this article:}

I Gusti Ayu Trisna Windiani, Putu Diah Vedaswari, Eka Gunawijaya, Ni Putu Veny Kartika Yantie, I Gusti Agung Ngurah Sugitha Adnyana, Soetjiningsih. Correlation Between Quality of Life and Severity of Valve Abnormalities in Children with Rheumatic Heart Disease. American Journal of Pediatrics. Vol. 6, No. 2, 2020, pp. 78-82. doi: 10.11648/j.ajp.20200602.11

Received: February 12, 2020; Accepted: February 24, 2020; Published: March 3, 2020

\begin{abstract}
Rheumatic heart disease (RHD) is one of the chronic diseases that affects the heart valve and requires long-term treatment that can affect the quality of life. We aimed to determine the correlation between quality of life and severity of valve abnormalities in children with rheumatic heart disease. This was a cross-sectional study was performed to 28 children with RHD aged 2 to 18 years old who treated at Integrated Cardiovascular Outpatient Clinic of Sanglah General Hospital from March to April 2018. Patients suffering from other chronic diseases or neurodevelopmental disorders were excluded. Assessment of the quality of life using PedsQL version 4.0 Generic Core Scales questionnaire. Assessment of severity of valve abnormalities using echocardiographic score. Analysis was performed using Spearman correlation test, confident interval (CI) $95 \%$, significant if $\mathrm{p}<0.05$. We found the patients mean age was 12.75 years old and mostly men ( 18 subjects). Most isolated abnormality was mitral valve (17 subjects), with most involved more than one valve (22 subjects). Almost patients treated with Benzathine penicillin $\mathrm{G}$ (25 subjects) as secondary prophylaxis. The mean score of quality of life from the children's report was $78.05 \pm 14.66$ and from the parent' report was $79.69 \pm 14.36$. The lowest mean score of quality of life is from school function. Between quality of life and severity of valve abnormalities found a weak negative correlation $(r=-0.377 ; p=0.048)$. There was a weak negative correlation between quality of life and severity of valve abnormalities in children with rheumatic heart disease.
\end{abstract}

Keywords: Quality of Life, Children, Rheumatic Heart Disease, Echocardiographic Score

\section{Introduction}

Rheumatic heart disease is a disease caused by damage of the heart valve caused by an abnormal immune response to group A Streptococcal infections that mostly occur in childhood. This disease is a major cause of heart failure in children and young adults, causing disability and premature death, also affecting the ability to work in many countries worldwide [1].

Improvements in economic levels, nutrition, access to health services and the discovery of penicillin have changed the epidemiological trend of acute rheumatic fever and rheumatic heart disease [1]. Mortality rate of children with heart disease have decreased dramatically in the last decade, but this resulting in an increasing number of survivor with morbidities that impact their quality of life [2]. For this reason, more attention is needed to focus on outcomes of therapy and the quality of life of patients to obtain optimal levels of health.

Quality of life (QoL) is defined as a multidimensional construct integrating physical, emotional, and social well-being and functioning as perceived by the individual [3]. Quality of life consists of two components. The first component is physical aspect which includes general health, diet, body built, mental health, pain and disease. The second component is psychological aspect including stress, anxiety, satisfaction and positive and negative emotional conditions 
[4]. Many studies assessed the quality of life of children with heart disease but few focusing on the quality of life in children with rheumatic heart disease.

Measuring QoL to gain a better understanding patients' point of view is used in routine clinical trials. The measurement of QoL can be used by healthcare providers to obtain a holistic view of children's subjective well-being in several domains of their daily life. Quality of life studies involving pediatric patients with chronic diseases and their parents can help health practitioners to more fully understand children's disease-specific symptoms, psychosocial functioning and development in the context of daily life [5].

There are several instruments that are used to assess the QoL of children. The general QoL assessment instrument that is widely used and already validated in Indonesian is The Pediatric Quality of Life Inventory (PedsQL $\left.{ }^{\mathrm{TM}}\right)$. PedsQL ${ }^{\mathrm{TM}}$ is an instrument that assesses the quality of life related to health in children and adolescents aged from 2 to 18 years. The PedsQL $^{\mathrm{TM}}$ 4.0 Generic Core Scales is a multidimensional (physical, emotional, social, school function) measurement based on self-reports and parent reports that are developed as measurements related to health in general that can be applied to healthy children and children with chronic health conditions [6-8].

Children with chronic diseases are known to have a higher risk to have lower quality of life than healthy children. Various factors are said to influence the assessment of a child's quality of life such as the level of education of the parents, the socioeconomic level of the family, the duration of illness and the severity of the disease. There was evidence showed a decline in the quality of life of children in rheumatic heart disease, but few studies have assessed the relationship between the quality of life of children and the severity of the disease. The echocardiographic score is one of the assessments of valve abnormalities based on echocardiographic examination result that used in heart valve disease. The greater the score, the higher the severity of valve abnormalities [9]. Therefore, we want to assess the correlation between quality of life and severity of valve abnormalities in children with rheumatic heart disease.

\section{Methods}

Sample were consecutively selected from all children with heart disease aged 2 to 18 years, who treated at Integrated Cardiovascular Outpatient Clinic of Sanglah General Hospital from March to April 2018 that full filled inclusion criteria. Inclusion criteria are children who suffer from rheumatic heart disease, aged 2-18 years and parents willing to participate in the study. All children suffering from other chronic diseases such as asthma, tumors, cancer, cerebral palsy, diabetes, chronic kidney disease and neurodevelopmental disorders were excluded. Interviews and questionnaires were completed while waiting for a doctor's examination.

Rheumatic heart disease defined as sequelae due to carditis from previous rheumatic fever diagnosed by cardiac consultant pediatrician. Health-related quality of life was the perception of children and families about the impact of disease and its treatment on daily life, which is obtained from the results of the PedsQL ${ }^{\mathrm{TM}}$ 4.0 Generic Core Scales questionnaire. Parental education was the last education taken by parents who fill out questionnaires, divided into low education (not schooling, graduated from elementary school, or junior high school) and high education (graduated from senior high school or college). Parental occupation was the last job of parents who fill out questionnaires, differentiated into unemployee, government employee, private employees, or entrepreneurs. Parents income was the total income of both parents for one month divided into $<$ IDR 2,000,000 and $\geq$ IDR 2,000,000.

Valve abnormalities were sequelae of carditis that affects the heart valves which are known from the results of echocardiography examination. The valve abnormalities can be either mitral regurgitation (MR) and / or aortic regurgitation (AR). Secondary prophylaxis was drugs given to prevent recurrent rheumatic fever. The drug can be Benzathine penicillin $\mathrm{G}$ injection or oral erythromycin. Anti-heart failure medication was drugs given to patients who have heart failure due to rheumatic heart disease by a pediatrician known from medical records. The echocardiographic score was use to assess the severity of heart valve abnormalities with a minimum score of three and a maximum of six, which consists of the following assessments (table 1) [9]:

Table 1. Echocardiographic score for valvular heart disease.

\begin{tabular}{lll}
\hline \multirow{2}{*}{ Echo finding } & Score & \\
\cline { 2 - 3 } & $\mathbf{1}$ & $\mathbf{2}$ \\
\hline Valve lesion echo severity & Moderate & Severe \\
\hline $\begin{array}{l}\text { Pulmonary hypertension } \\
(\% \text { of pulmonary to systemic blood pressure) }\end{array}$ & $50-75 \%$ & $>75 \%$ \\
$\mathrm{LV}^{+}$(d) z score & $1-3$ & $>3$ \\
\hline
\end{tabular}

$+\mathrm{LV}=$ left ventricle.

The research tool used in this study was an informed consent form, the research form contained study numbers, filling dates, patient data and parent data. The PedsQL ${ }^{\mathrm{TM}} 4.0$ Generic Core Scales questionnaire was used to assess quality of life based on child self-report and parent proxy-reports. This questionnaire consists of 23 questions encompass physical functioning ( 8 items), emotional functioning (5 items), social functioning (5 items), and school functioning (5 items). The PedsQL 4.0 Generic Core Scales are comprised of parallel child self-report and parent proxy-report formats. Child self-report includes ages 5-7, 812, and 13-18 years. Parent proxy-report includes ages 2-4 (toddler), 5-7 (young child), 8-12 (child), and 13-18 (adolescent). The assessment in each questionnaire item was given with the numbers $0,1,2,3,4$ (0: never, 1: almost never, 2: sometimes, 3 : often, 4 : almost always), then converted into scores with a range of $0-100(0=100,1=75,2=50,3=25$, $4=0$ ). The score is summed and then divided by the total questions answered. The higher the score obtained the better 
the quality of life of the patient [10].

Data characteristics of the subjects and the rheumatic heart disease are presented in means and absolute numbers. Normality test using the Shapiro-Wilk test. To determine the correlation between the quality of life quality of children with the severity of heart disease using the Spearman correlation test. The level of correlation is distinguished by: 0.00-0.199 = very weak correlation; $0.20-0.399=$ weak correlation; $0.40-0.599=$ moderate correlation; $0.60-0.799=$ strong correlation; $0.80-1.000=$ very strong correlation. The statistical test was significant if the value is $\mathrm{p} \leq 0.05$ [11].

\section{Results}

During the study period, a total of 28 children came to the clinic and all met the inclusion criteria. No samples in the age group of 2-4 years and 5-7 years. Most of the research samples aged 13-18 years with an average age of 12.75 years and male (18 subjects). Characteristic of 28 subjects were shown in Table 2. All of the PedsQL parent report questionnaire completion was done by the patient's mother. There was total 15 mothers with higher education and the majority of the mothers work as entrepreneurs. Half of the subjects have family income below Rp. 2,000,000.

Table 2. Socio-demographic characteristics of the study sample.

\begin{tabular}{ll}
\hline Characteristic & RHD, $\mathbf{n}=\mathbf{2 8}$ \\
\hline Age (year), means (SD) & $12.75(1.97)$ \\
Age group (year), $\mathrm{n}$ & \\
$8-12$ & 12 \\
$13-18$ & 16 \\
Sex, $\mathrm{n}$ & \\
Male & 18 \\
Female & 10 \\
Parental education, $\mathrm{n}$ & \\
Low & 13 \\
High & 15 \\
Parental occupation, $\mathrm{n}$ & \\
Unemployee & 6 \\
Government employee & 0 \\
Private employee & 7 \\
Entrepreneur & 15 \\
Parents income, $\mathrm{n}$ & \\
$<$ Rp 2.000.000 & 14 \\
$\geq$ Rp 2.000.000 & 14 \\
\hline
\end{tabular}

Most subjects have suffered from rheumatic heart disease for 2 years. All of the valve abnormalities found was valve regurgitation, there was no valve stenosis or calcification. The most common isolated valve is the mitral valve (17 subjects), followed by the aortic valve (11 subjects). Most subjects suffered more than one valve abnormality (22 subjects). All subjects received secondary prophylaxis, with 25 subjects receiving intramuscular Benzathine penicillin $G$ injections every 21 days, 3 other subjects receiving oral erythromycin $250 \mathrm{mg}$ every 12 hours every day. A total of 16 subjects also received oral anti-failure (table 3 ).
Table 3. Medical characteristics of the study sample.

\begin{tabular}{ll}
\hline Characteristic & RHD, $\mathbf{n}=\mathbf{2 8}$ \\
\hline Duration of illness (year), means (SD) & $2(1.5)$ \\
Valve abnormality, $\mathrm{n}$ & \\
$\mathrm{MR}^{+}$ & 17 \\
$\mathrm{AR}^{*}$ & 3 \\
MR and AR & 8 \\
Number of valve involved, $\mathrm{n}$ & \\
1 valve & 6 \\
$>1$ valve & 22 \\
Echocardiographic score, $\mathrm{n}$ & \\
3 & 18 \\
4 & 5 \\
5 & 4 \\
6 & 1 \\
Secondary prophylaxis, $\mathrm{n}$ & \\
Benzathin penicillin G injection & 25 \\
Erithromycin oral & 3 \\
Antifailure therapy, $\mathrm{n}$ & \\
Yes & 16 \\
No & 12 \\
\hline
\end{tabular}

$+\mathrm{MR}=$ mitral regurgitation, $* \mathrm{AR}=$ aorta regurgitation.

All questions in the PedsQL questionnaire can be answered by children and parents. The average value of total QoL based on parental reports is almost the same as the reports of children, with a moderate positive correlation with a value of $0.475(\mathrm{p}=0.008)$. The highest mean value was obtained on social functions based on self-reports $(86.33 \pm 52)$ and parent reports $(90.66 \pm 9.62)$ while the lowest mean score was obtained for school functions both in child reports $(69.66 \pm 19.94)$ and parental reports $(69.66$ $\pm 20.99)$. The relationship between the quality of life quality based on self-report and the severity of valve abnormalities showed a weak negative correlation $(\mathrm{r}=$ $-0,377 ; \mathrm{p}=0.048)$.

\section{Discussion}

The prevalence of rheumatic heart disease in Indonesia is still high, amounting to $0-8$ cases per 1000 in school children aged 5-14 years [12]. The average age of subjects in this study was 12.75 years, its accordance with the range of prevalence of rheumatic heart disease in children, while the most genders are men. Some previous studies found more prevalence in women $[13,14]$ while the meta-analysis of 33 studies found no significant difference for sex in rheumatic heart disease [15].

One of the predisposing factors for rheumatic heart disease was low socio-economic status [13]. The higher level of family economic status will increase attention to children's health, including sources of funds for the treatment of children. It also influences information about health obtained by parents, either through printed media or audio-visual media. Low income related to low socio-economic status tends to ignore the needs of children and thus affect the quality of life of children. In this study, found the same 
number of subjects between families with income of less than Rp 2,000,000 and $\geq \operatorname{Rp~2,000,000~per~month.~}$

In this study, the valve abnormality that occurred was valve regurgitation, no subjects with valve stenosis were found. Valve regurgitation results from edema with thickening of fibrous tissue with minimal calcification, and anterior cord elongation [16]. The most common valve affected in this study was mitral valve, followed by aortic valve. This is consistent with previous study found that the most common valve abnormality was the mitral valve (85\%) [15]. The study also mentioned the tricuspid valve is rarely affected, whereas the pulmonary valve is almost never affected $(<5 \%)$. Several other studies also found the mitral valve as the valve most often affected [17-19].

Of the 28 subjects who received secondary prophylaxis, three subjects received oral erythromycin due to an allergic reaction to Benzathine penicillin $G$. This value was higher compared to the previous study which had $3.2 \%$ of their study subjects experiencing an allergic reaction to penicillin [20].

In this study the results of PedsQL ${ }^{\mathrm{TM}} 4.0$ based on self-reports and parent reports show that QoL was still good. Only in the subset of school functioning, means of self-reports and parent reports are below the average value of total QoL. Most studies showed that the QoL of children with heart disease was lower than normal children, but some studies found that the QoL of children with heart disease was still good [4, 8]. The total QoL based on self-reports and parent reports was high in this study could be related to several factors, such as children's coping with their disease and their response to the chronic illness stress, where they were enabled cope with significant adverse events and still function completely. Supporting the development of this coping mechanism in children will help children achieve positive outcomes [4].

In this study only school functioning showed a score lower than the total score of QoL, both from self-reports and parent reports. The same result was found in previous studies. School functioning have the lowest scores caused by children often absent at the school. In addition, it is estimated that children with heart disease have a higher number of neurodevelopmental problems, related to motor control and expressive language, visual motor integration, learning, and concentration of attention [8].

The higher echocardiographic score indicates more severe the heart valve abnormality. This study found a negative correlation between the quality of life based on the assessment of children with echocardiographic scores. It means that the higher the echocardiographic score; in other words the more severe the disease, the lower the quality of life of the child. Weak correlation found may be due to other factors that influence the assessment of children's QoL in addition to problems with the disease. A study of children with heart disease also had significantly lower physical function score in children with more severe degrees of illness [6].

Identification of children with low QoL is important to be able to increase the outcome of children with rheumatic heart disease. Regular assessment of QoL is one way to detect the impact of chronic diseases for both physical and psychosocial aspects. PedsQL 4.0 Generic Core Scale is a short and standardized instrument that assesses patient and parental perceptions about the quality of life related to health in pediatric patients systematically with chronic health problems. The flexibility, reliability and validity of the PedsQL module makes it a popular tool in various clinical studies and applicable in the conditions of chronic childhood diseases. The provision of counseling and other interventions is primarily aimed at children with severe RHD so that they are expected to improve the quality of life of these children. Early identification regarding the inability of school functions, including problems in focusing attention, is urgently needed, including the intervention program on problems found.

The limitations of this study are researcher did not assess whether there was a history of repeated rheumatic fever in subjects and correlation between quality of life with other factors that might influence such as the type of secondary prophylaxis, administration of anti-failure, etc.

\section{References}

[1] Marijon, E., Mirabel, M., Celermajer, D. S., Jauven, X. (2012). Rheumatic heart disease. Lancet, 379: 953-64.

[2] Marino, B. S., Tomlinson, R. S., Drotar, D., Claybon, E. S., Aguirre, A., Ittenbach, R., Welkom, J. S., Helfaer, M. A., Wernovsky, G., Shea, J. A. (2009). Quality-of-life concerns differ among patients, parents and medical providers in children and adolescents with congenital and acquired heart disease. Pediatrics, 123: e708-e715.

[3] Goldbeck, L., Melches, J. (2005). Quality of life in families of children with congenital heart disease. Quality of Life Research, 14: $1915-1924$.

[4] Essawy, M. A. E., Bahgat, Z. S., Kassem, H. A. (2010). Health-related quality of life of school-age children with rheumatic fever. J Egypt Public Health Assoc, 85 (3): 2015-222.

[5] Capitello, T. G., Fiorilli, C. F., Placidi, S., Vallone, R., Drago, F., Gentile, S. (2016). What factors influence parents' perception of the quality of life of children and adolescents with neurocardiogenic syncope? Health and Quality of Life Outcomes, 14: 79.

[6] Uzark, K., Jones, K., Burwinkle, T. M., Varni, J. W. (2003). The Pediatric Quality of Life Inventory ${ }^{\mathrm{TM}}$ in children with health disease. Progress in Pediatric Cardiology, 18: 141-148.

[7] Varni, J. W., Limbers, C. A. (2009). The Pediatric Quality of Life Inventory: measuring pediatric health-related quality of life from perspective of children and their parents. Pediatr Clin N Am, 56: 843-863.

[8] Uzark, K., Jones, K., Slusher, J., Limbers, C. A., Burwinkle, T. M., Varni, J. W. (2016). Quality of life in children with heart disease as perceived by children and parents. Pediatrics, 121: 1060-1067. 
[9] Jamaledeen, M., Ali, S. K. M. (2012). Correlation of clinical and echo-cardiographic scores with blood "brain natriuretic peptide" in paediatric patients with heart failure. East African Medical Journal, 89: 359-362.

[10] Varni, J. W., Burwinkle, T. M., Seid, M., Skarr, D. (2003). The PedsQL 4.0 as a pediatric population health measure: feasibility, reliability, and validity. Ambul Pediatr, 3 (6): 329-341.

[11] Sugiyono. (2011). Statistika untuk penelitian. Bandung: Alfabeta.

[12] Carapetis, J. R. (2008). Rheumatic herat disease in Asia. Circulation, 118: 2748-2753.

[13] Riaz, B. K., Selim, S., Karim, N., Chowdhury, K. N., Chowdhury, S. H., Rahman, R. (2013). Risk factors of rheumatic heart disease in Bangladesh: a case-control study. J Health Popul Nutr, 31: 70-7.

[14] Watkins, D. A., Johnson, C. O., Colquhoun, S. M., Karthikeyan, G., Beaton, A., Bukhman, G., et al. (2017). Global, regional, and national burden of rheumatic heart disease, 1990-2015. N Engl J Med, 377: 713-722.

[15] Rothenbuhler, M., O'Sullivan, C. J., Stortecky, S., Stefanini, G. G., Splitzer, E., Estill, J., dkk. (2014). Active surveillance for rheumatic heart disease in endemic regions: a systematic review and meta-analysis of prevalence among children and adolescents. Lancet Globe Health, 2: 717-726.

[16] Sliwa, K., Carrington, M., Bongani, M., Zigiriadis, E., Mvungi, R., Stewart, S. (2009). Incidence and characteristics of newly diagnosed rheumatic heart disease in urban African adults: insights from the Heart of Soweto Study. Eur Heart J, 31: 719727.

[17] Essien, I. O., Onwubere, B. J., Anisiuba, B. C., Ejim, E. C., Andy, J. J., Ike, S. O. (2008). One year echocardiographic study of rheumatic heart disease at Enugu, Nigeria. Niger Postgrad Med J, 15: 175-178.

[18] Sani, M. U., Karaye, K. M., Borodo, M. M. (2007). Prevalence and pattern of rheumatic heart disease in the Nigerian savannah: an echocardiographic study. Cardiovasc J Afr, 18: 295-299.

[19] Markowitz, M., Lue, H. C. (1996). Allergic reactions in rheumatic fever patients on long-term benzathine penicillin G: the role of skin testing for penicillin allergy. Pediatrics, 981-983.

[20] Ariani, Novira, R. Y., Yosoprawoto, M. (2012). Kualitas hidup anak dengan penyakit jantung. Jurnal Kedokteran Brawijaya, 27 (1): 56-60. 